\title{
How reliable is the diagnosis of lung cancer using small biopsy specimens? Report of a UKCCCR ${ }^{\star}$ Lung Cancer Working Party
}

J St J Thomas, D Lamb, T Ashcroft, B Corrin, C W Edwards, A R Gibbs, W E Kenyon, R J Stephens, W F Whimster
Department of Pathology, Western General Hospital, Edinburgh EH4 2XU J St J Thomas

University Medical School, Edinburgh

D Lamb

Freeman Hospital, Newcastle upon Tyne T Ashcroft

Royal Brompton

National Heart and

Lung Hospital,

London

B Corrin

Birmingham

Heartlands Hospital,

Birmingham

C W Edwards

Llandough Hospital, Penarth, South

Glamorgan

A R Gibbs

Broadgreen Hospital,

Liverpool

W E Kenyon

Medical Research

Council Cancer Trials

Office, Cambridge

R J Stephens

King's College

Hospital Medical

School, London

W F Whimster

Correspondence to:

Dr J St J Thomas

Received 29 March 1993

Returned to authors

30 June 1993

Revised version received

13 July 1993

Accepted 16 July 1993

*United Kingdom Coordinating Committee for Cancer Research

\begin{abstract}
Background-A study was undertaken to investigate the accuracy of typing of a series of bronchial carcinomas by experienced pathologists with an interest in lung cancer from the examination of bronchoscopic biopsy specimens.

Methods-Eighty bronchial biopsy specimens showing positive results for bronchial carcinoma were circulated to five pathologists, who recorded diagnostic criteria and diagnosis for each. Diagnoses were then compared with the diagnosis agreed from the resection specimen corresponding to each biopsy specimen. A "non-small cell carcinoma, not further specified" classification group was introduced for small biopsy specimens.

Results-A diagnostic accuracy of $75 \%$ was achieved for squamous cell carcinomas, $\mathbf{6 6 \%}$ for small cell carcinomas, and $50 \%$ for adenocarcinomas. There was diagnostic confusion between small cell and non-small cell carcinoma in less than $10 \%$ of cases. The introduction of a non-specific non-small cell classification improved diagnostic accuracy by $10-15 \%$ for each non-small cell tumour group. Conclusions-There are appreciable inaccuracies in applying the World Health Organisation's 1981 classification of lung cancer to the diagnosis of bronchial carcinoma from small biopsy specimens and these inaccuracies have been measured. They can be diminished by introducing a less specific "non-small cell" category for use with this sort of biopsy material. Care should be taken not to overinterpret small biopsy specimens in lung cancer.
\end{abstract}

(Thorax 1993;48:1135-1139)

Different histological subtypes of lung cancer (appendix 1) undoubtedly respond to different therapeutic regimens, ${ }^{1-5}$ but patients are often given specific treatments from the results of typing performed on small bronchoscopic biopsy specimens, which may not be representative of the whole tumour.

As the proportion of unrepresentative or misclassified small biopsy specimens is not known, the problem was explored by a group of experienced histopathologists with a special interest in lung cancer. Noting that there was no scope within the 1981 classification of the World Health Organisation to make a non-specific diagnosis which could be refined later if further tissue became available ${ }^{6}$ we addressed the question: what percentage of the different cell types are correctly diagnosed compared with those that are either not specifically diagnosed or incorrectly diagnosed?

The results of a parallel analysis of the accuracy of tumour diagnosis and classification using cytological material was also carried out and will be published elsewhere.

\section{Methods}

The histological subtypes set out in appendix 2 and based on the 1981 WHO classification were first agreed. This modified the WHO classification in that category 4 allows the grouping together of unusual tumours such as adenosquamous carcinoma and carcinoid tumours, and category 5 allows for a diagnosis of "non-small cell carcinoma, not otherwise specified." The diagnostic criteria for each subtype were agreed after lengthy discussions by the whole group (appendix 3). The numbering of these criteria is used in the same way throughout this paper. The criteria are grouped together because of assumed associations with particular tumour types: criteria 1-4 with squamous carcinoma, 5-13 with small cell carcinoma, and 14-18 with adenocarcinoma. Definitions of the diagnostic criteria and diagnostic categories are listed in appendix 4.

Eighty biopsy specimens of lung cancer were retrieved from the departmental files of the participating pathologists; contemporaneous cytological specimens and resection specimens were also available. All biopsy specimens were of the type obtained during fibreoptic bronchoscopy. Sections stained by haematoxylin and eosin and alcian blue/periodic acid-Schiff-diastase (AB/PAS-D) were available for examination. This selection inevitably resulted in the underrepresentation of small cell carcinomas because they are less often removed surgically (see table 1 ).

The 80 small biopsy specimens (single slides $+\mathrm{AB} / \mathrm{PAS}-\mathrm{D}$ ) were sent in turn to five participating pathologists, who returned their findings for each of the diagnostic criteria and 
their diagnoses to the central coordinator (RJS) for collation and analysis. To examine the criteria used for diagnosis of the subtypes the pathologists were instructed to examine each criterion in turn, recording a positive or negative as appropriate before recording their diagnoses. The resected tumours (multiple slides) corresponding to the small biopsy specimens were circulated to three pathologists, who agreed the diagnoses and the diagnostic criteria.

\section{Results}

The small biopsy material provided a total of 400 possible diagnoses ( 80 cases or slides $\times$ five participating pathologists).

\section{ACCURACY OF BIOPSY DIAGNOSES}

The number of cases of each type as judged by the resected specimens is shown in relation to the typing of small biopsy specimens by the five pathologists in table 1 .

The vertical total column gives the distribution of the observations of the five pathologists in relation to the small biopsy specimens; the horizontal row gives the distribution of the observations of the five pathologists in relation to the resected specimens. Note that undifferentiated large cell carcinomas were not expected to be recognised in the small biopsy specimens.

Within the matrix "correct" attributionsthat is, the biopsy typing coincided with the resection typing-are in bold, "wrong" attributions-that is, the biopsy typing did not coincide with the resection typing-are in italic type, and "not incorrect" attributionsthat is, the biopsy typing was correct as far as it went, such as a biopsy typing of non-small cell carcinoma relating to a resection typing of adenocarcinoma - are in plain type.

Table 2 shows that the small biopsy specimens from the squamous carcinomas were wrongly typed by the five pathologists in $9 \%$ $(20 / 210)$ of readings, small cell carcinomas in $7 \%(2 / 30)$, and adenocarcinomas in $22 \%$ $(22 / 100)$; they were correctly typed as squa-

Table 1 Accuracy of diagnoses from small biopsy specimens compared with resection diagnoses. Values are numbers of observations from 80 cases*

\begin{tabular}{|c|c|c|c|c|c|c|}
\hline \multirow[b]{2}{*}{$\begin{array}{l}\text { Diagnosis from small } \\
\text { biopsy specimen } \dagger\end{array}$} & \multicolumn{6}{|c|}{ Resection diagnosis } \\
\hline & Squamous & $\begin{array}{l}\text { Adeno- } \\
\text { carcinoma }\end{array}$ & $\begin{array}{l}\text { Small } \\
\text { cell }\end{array}$ & $\begin{array}{l}\text { Undifferentiated } \\
\text { large cell }\end{array}$ & Carcinoid & Total \\
\hline (1) Squamous & 155 & 16 & 1 & 1 & 1 & 174 \\
\hline (2) Small cell & 2 & 0 & 21 & 0 & 3 & 26 \\
\hline (3) Adenocarcinoma & 4 & 47 & 0 & 1 & 9 & 61 \\
\hline (4) Other & 14 & 6 & 0 & 1 & 18 & 39 \\
\hline $\begin{array}{l}\text { (5) No differentiation } \\
\text { (not small cell) }\end{array}$ & 22 & 28 & 2 & 17 & 3 & 72 \\
\hline $\begin{array}{l}\text { (6) No differentiation } \\
\text { (unclassified) }\end{array}$ & 7 & 1 & 3 & 2 & 0 & 13 \\
\hline (7) Not typable & 3 & 1 & 3 & 2 & 1 & 10 \\
\hline (8) Not classified & 3 & 1 & 0 & 1 & 0 & 5 \\
\hline Total diagnoses & 210 & 100 & 30 & 25 & 35 & 400 \\
\hline Total cases & 42 & 20 & 6 & 5 & 7 & 80 \\
\hline
\end{tabular}

$\star$ Bold type $=$ correct; italic $=$ wrong, plain $=$ not incorrect.

+ Number is category given in appendices 2 and 4 .
Table 2 Percentages of accurate diagnoses from small biopsy specimens compared with resection diagnoses

\begin{tabular}{llll}
\hline & \multicolumn{3}{l}{ Diagnosis } \\
\cline { 2 - 4 } Tumour type ${ }^{*}$ & Correct & Not incorrect & Wrong \\
\hline Squamous & 74 & 17 & 9 \\
Small cell & 70 & 23 & 7 \\
Adenocarcinoma & 47 & 31 & 22 \\
Large cell & 68 & 20 & 12 \\
Carcinoid & 51 & 17 & 32 \\
\hline
\end{tabular}

${ }^{\star}$ From resection diagnosis.

mous carcinomas in $74 \%(155 / 210)$, small $\vec{\omega}$ cell carcinomas in $70 \%(21 / 30)$, and adenocarcinomas in $47 \%(47 / 100)$. The squamous $\times$ carcinomas were not incorrectly typed in $17 \% \stackrel{\oplus}{\infty}$ $(35 / 210)$, the small cell carcinomas in $23 \% \overrightarrow{-}$ $(7 / 30)$, and the adenocarcinomas in $31 \%$ (31/100). No pathologist typed any of the $\vec{\omega}$ undifferentiated large cell carcinomas as small $\mathrm{O}$ cell carcinoma, although on one occasion a small cell carcinoma was diagnosed as being $z$ squamous and on another as non-small cell, not further specified (category 5). The carci- $\frac{\Phi}{3}$ noid tumours were diagnosed correctly on $\mathbb{\mathbb { D }}$ $51 \%$ of occasions, not incorrectly on $17 \%$ of occasions, and wrongly on $32 \%$ of occasions. One of the carcinoids was called an adenocarcinoma by all five pathologists who examined the biopsy but was undoubtedly a carcinoid on the corresponding resection specimen.

\section{AGREEMENT AMONG PATHOLOGISTS ABOUT} DIAGNOSES

Table 3 shows that a unanimous or near unanimous (4/5 agreement) diagnosis of squamous carcinoma was made in $76 \%$ of cases, whereas in adenocarcinoma this only occurred in $35 \%$ of cases. Cases with complete disagreement are not shown.

\section{AGREEMENT OF CRITERIA}

Table 4 shows the agreement among pathologists about the presence of a criterion $\frac{\text { o }}{2}$ (defined as all or four out of five pathologists $\frac{7}{O}$ agreeing) or absence of a criterion (defined as all or four out of five pathologists agreeing).

For our squamous criteria there was approximately $80 \%$ agreement about the presence or absence of keratinisation, prick- $\omega$ les, and stratification. There was less than $40 \%$ agreement and less than $10 \%$ unanimity

Table 3 Level of agreement among five pathologists about diagnoses from biopsy specimens for different tumour types as determined by resection diagnosis. Values are numbers of cases

\begin{tabular}{llll} 
numbers of cases & \multicolumn{3}{l}{ No of pathologists agreeing } \\
\cline { 2 - 4 } Resection diagnosis & Five & Four & Three \\
\hline Squamous & 20 & 13 & 4 \\
Small cell & 3 & 1 & 0 \\
Adenocarcinoma & 4 & 3 & 3 \\
Other specified & 1 & 3 & 1 \\
No differentiation & 1 & 7 & 8
\end{tabular}

^Not small cell lung carcinoma. 
Table 4 Interobserver agreement on presence or absence of criteria for 80 cases. Values are percentages

\begin{tabular}{|c|c|c|c|}
\hline Criterion & Presence agreed & Absence agreed ${ }^{\star}$ & No agreement \\
\hline Keratinisation & 24 & 64 & 12 \\
\hline Intercellular prickles & 19 & 61 & 20 \\
\hline Stratification & 31 & 54 & 15 \\
\hline Polygonal cell shape & 29 & 17 & 54 \\
\hline High nucleocytoplasmic ratio & 9 & 80 & 11 \\
\hline Fine stippling of chromatin & 7 & 80 & 13 \\
\hline Conspicuous nucleoli & 18 & 49 & 33 \\
\hline Basophilic cuffing & 0 & 100 & 0 \\
\hline Nuclear moułding & 3 & 90 & 7 \\
\hline Stromal desmoplasia & 4 & 88 & 8 \\
\hline Formation of rosettes & 0 & 99 & 1 \\
\hline Fusiform pattern & 2 & 87 & 11 \\
\hline Pagetoid infiltration of surface epithelium & 0 & 99 & 1 \\
\hline Acini & 10 & 71 & 19 \\
\hline Cribriform pattern & 0 & 94 & 6 \\
\hline Papillary pattern & 3 & 95 & 2 \\
\hline Alveolar pattern & 0 & 100 & 0 \\
\hline Mucus formation & 8 & 84 & 8 \\
\hline
\end{tabular}

${ }^{\star}$ By all five or four out of five pathologists.

about polygonal cell shape (criterion 4), which is therefore a poor diagnostic criterion for squamous carcinoma.

There was good agreement about the presence or absence of all small cell carcinoma criteria with the exception of the presence or absence of nucleoli. Given the importance of the identification of nucleoli as a negative diagnostic feature of small cell carcinoma, this finding needs to be studied further.

All our adenocarcinoma criteria show more than $80 \%$ agreement, but the number of unanimous positives is low and this is probably a significant finding in relation to our poor diagnostic accuracy for this group of tumours.

\section{PREDICTIVE VALUE OF CRITERIA}

We have not examined in detail specific correlations between the recording of a particular criterion and making a particular diagnosis. There is a relatively good correlation between our predetermined squamous carcinoma criteria (1-4, appendix 3 ) and squamous carcinoma diagnoses, with only very occasional adenocarcinoma criteria (14-18) being recorded. Criterion 5 (high nucleocytoplasmic ratio) also seems to be represented in substantial numbers $(33 / 210$ incidents) and is therefore a poor criterion for distinguishing, for example, squamous carcinoma from small cell carcinoma.

Analysis of our results for criteria recorded for small cell carcinoma is hampered by the small number of cases studied. In addition,

Table 5 Differences in the percentages of principal diagnoses made on biopsy and resection specimens

\begin{tabular}{|c|c|c|c|c|c|}
\hline \multirow[b]{2}{*}{ Specimen } & \multicolumn{5}{|l|}{ Diagnosis } \\
\hline & Squamous & Small cell & Adeno & Other specified & $\begin{array}{l}\text { Non-small cell not } \\
\text { otherwise specified }\end{array}$ \\
\hline $\begin{array}{l}\text { Biopsy } \\
\text { Resection }\end{array}$ & $\begin{array}{l}38 \\
47\end{array}$ & $\begin{array}{l}9 \\
6\end{array}$ & $\begin{array}{l}15 \\
21\end{array}$ & $\begin{array}{r}8 \\
16\end{array}$ & $\begin{array}{r}21 \\
5\end{array}$ \\
\hline
\end{tabular}

absolute criteria for this tumour were not available and we were trying to establish them. We also included features that were believed not to be present in small cell carcinoma-namely, stromal desmoplasia and prominent nucleoli. The following criteria proved, however, to be frequently positive: high nucleocytoplasmic ratio $(24 / 30(80 \%))$, chromatin stippling $(19 / 30(63 \%))$, nuclear moulding (16/30 (53\%)), and fusiform pattern $(13 / 30(43 \%))$. With very few exceptions, our criteria for non-small cell carcinoma were not observed in our cases of small cell carcinoma.

The criteria recorded for the adenocarcinomas are not as tightly confined to criteria 14-18 (appendix 3) as they would be if there was absolute correspondence. For example, criterion 4 (polygonal cell shape) was recorded on $57 \%$ of occasions and is therefore of little value in discriminating adenocarcinoma from squamous carcinoma.

\section{BIOPSY $v$ RESECTION DIAGNOSES}

Table 5 shows the change in distribution of diagnoses in the resection specimens compared with their corresponding biopsy specimens. The principal difference was a substantially reduced number of non-specific (principally category 5) diagnoses in the resection cases. This is to be expected given the greater amount of material available for examination.

\section{Discussion}

POOR TYPING ACCURACY

The diagnosis of lung cancer itself is reliable in small biopsy specimens but the diagnosis of subtypes on which treatment is decided is unreliable. The shortcomings stem both from inappropriate application of the existing classification and also from inadequacies of the classifications themselves. ${ }^{7-9}$ In particular, the existing classifications fail to allow for the small biopsy specimens to be representative enough for specific categorisation of a tumour. The introduction of the two categories, non-small cell carcinoma of specified type and non-small carcinoma, not otherwise specified (categories 4 and 5 in appendix 2) in our provisional classification has allowed us to explore the scale of this problem and provide answers to most of our original questions.

We appreciate that this study does not entirely reflect what happens clinically, where additional cytological material might be available. It is accepted that the accuracy of tumour typing can be improved by coexamination of cytological material, but we decided at the outset of the study to run a parallel cytological study rather than a combined cytological-histological study, which might have confused our results.

SQUAMOUS $v$ ADENOCARCINOMA

Our results show that the accuracy of diagnosis from small biopsy specimens is strongly affected by tumour type- $-75 \%$ of squamous 
carcinomas versus less than $50 \%$ of adenocarcinomas, for which there is also poor unanimity of diagnosis. This may be because pathologists have difficulty in deciding, for example, how many acinar structures or how much mucin is required to diagnose adenocarcinoma. This is examined further in the discussion of criteria.

The review of the resected specimens was carried out on the basis of the WHO classification $^{6}$ rather than the modified form that we used for the biopsy specimens, which contains a number of catch all categories to enable the pathologist to subclassify a tumour while leaving scope for further refinement if more tissue is obtained by resection or at necropsy. It seemed preferable to make a diagnosis that was not incorrect-for example, non-small cell tumour, not otherwise specified (category 5)-which could be revised later, than to make one that was wrong because of inadequate sampling. It is, therefore, not surprising that the resection specimen diagnoses are more specific (table 5).

\section{SAMPLING AND ASSESSMENT OF THE TYPING CRITERIA}

A major problem in the diagnosis of tumours using small biopsy specimens is tumour heterogeneity. Classically this applies to tumours of mixed differentiation, but at a more subtle level all tumours are heterogeneous to some extent. ${ }^{10}$ Sampling errors for characteristics such as keratin or acinar formations will inevitably occur, and this study has attempted to measure this problem. Clearly, if a tumour is truly of mixed differentiation-for example, adenosquamous - the inherent sampling errors are likely to multiply.

Of our diagnostic criteria only polygonal cell shape proved to be worthless because of a lack of agreement among pathologists about its presence or absence. Sampling probably contributed significantly to the difficulty experienced in diagnosing carcinoid tumours.

HOW ACCURATE IS THE SEPARATION OF SMALL CELL FROM NON-SMALL CELL CARCINOMA USING SMALL BIOPSY SPECIMENS?

Our data show that $7 \%$ of small cell lung cancers were called non-small cell and that $3 \%$ of non-small cell carcinomas were called small cell. These figures would obviously benefit from a larger sample of small cell carcinomas than we had to study. However, three of our six cases were unanimously diagnosed as such while a fourth was diagnosed as small cell carcinoma by four out of five pathologists. The remaining two cases were diagnosed only by one out of five pathologists on each occasion while the majority of pathologists placed these cases in various unclassified or unclassifiable categories (categories 6, 7, and 8; appendix 2).

Our study material contained an excess of carcinoid tumours and small cell carcinomas were underrepresented. This, in fact, served to highlight the diagnostic difficulties encountered with this group of tumours, particularly confusion between small cell carcinoma and adenocarcinoma.

WHAT PERCENTAGE OF THE DIFFERENT CELI TYPES ARE CORRECTLY DIAGNOSED, INCORRECTLY DIAGNOSED, AND WRONGLY DIAGNOSED USING SMALL BIOPSY SPECIMENS? The percentage of wrong diagnoses is similars for each principal tumour group as were the results of correct diagnoses with the excep-을 tion of adenocarcinoma. The poor yield of

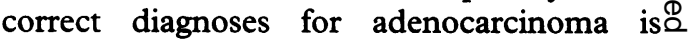
almost entirely accounted for by not incorrect diagnoses. It is difficult to imagine how these $\vec{\circ}$ non-specific diagnoses would have been allocated if there was no category 5 diagnostic $\vec{\omega}$ group available to us. Presumably the pathologist would have called the tumour poorly $\times$ differentiated and then made an educated guess as to the appropriate category for the $\overrightarrow{-}$ final diagnostic type.

CAN WHO (1981) BE APPLIED IN A MEANINGFUL WAY TO SMALL BIOPSY SPECIMENS?

We have shown the shortcomings of the $1981 \vec{z}$ WHO classification with small biopsy specimens. Table 5 shows a substantial drop in the 3 number of non-specific, non-small cell diag- $-\frac{\Phi}{-}$ noses made on resection specimens compared $\vec{\theta}$ with their corresponding biopsy specimens. This fall is parallelled by a rise in specific diagnoses. The major shortcoming of theo WHO (1981) classification is the lack of a diagnostic group that allows the tumour to be용 classified as non-small cell carcinoma with the view that this diagnosis may be refined $\stackrel{\varrho}{\rightrightarrows}$ further should more diagnostic materialo become available. The other principal area of difference in our provisional classification is the amalgamation of unusual specified tumours-for example, adenosquamous car-o cinoma and carcinoid tumours-into one $e_{x}^{0}$ group from which more detailed information may be abstracted subsequently. This gives $a$ less cumbersome classification that is easiero to manage and interpret.

Several problems could not be resolved by으 this study. For example, it is impossible to rule out that a diagnostic feature that was present in a resection specimen slide was not $\tilde{N}^{\circ}$ present in a particular corresponding biopsy specimen. Nevertheless, if pathologists unani-N్ mously record the presence of a feature in $a_{0}$ resection slide and its absence in a biopste specimen, the feature is unlikely to have been present in the biopsy slide.

Finally, pathologists in general might tendo to overinterpret small biopsy specimens and $\overrightarrow{0}$ offer information about the classification of a@ lung cancer which is not justified on the $e_{\Omega}^{\mathbb{P}}$ material available. Although we did not identify a serious degree of confusion between small cell and non-small cell carcinoma thato would have obvious therapeutic implications more subtle effects may arise as a consequence of inappropriate classification of nonsmall cell carcinomas. Furthermore, we are concerned that major therapeutic and epidemiological studies may be based on data that are flawed. Respiratory physicians, 
oncologists, pathologists, epidemiologists, and also research workers need to be aware of the limitations of tumour classification based on small biopsy material. We also emphasise that this study was carried out by pathologists with a special interest in the diagnosis and classification of lung cancer and that the diagnostic accuracy of this group may not be generally representative of diagnostic reporting in Britain.

\section{Appendix 1}

WHO (1981) CLASSIFICATION OF LUNG CANCER

(1) Squamous carcinoma (epidermoid carcinoma). Variant: spindle cell (squamous) carcinoma.

(2) Small cell carcinoma: oat cell carcinoma, intermediate cell type, and combined oat cell carcinoma.

(3) Adenocarcinoma: acinar adenocarcinoma, papillary adenocarcinoma, bronchioloalveolar carcinoma, and solid carcinoma with mucus formation.

(4) Large cell carcinoma. Variants: giant cell carcinoma, and clear cell carcinoma.

(5) Adenosquamous carcinoma.

(6) Carcinoid tumour.

(7) Bronchial gland carcinomas: adenoid cystic carcinoma, mucoepidermoid carcinoma, and others.

(8) Others.

\section{Appendix 2}

DIAGNOSTIC CATEGORIES USED IN THIS STUDY

(1) Squamous carcinoma.

(2) Small cell carcinoma.

(3) Adenocarcinoma.

(4) Non-small cell tumour of specified type.

(5) Non-small cell carcinoma, not otherwise specified.

(6) Malignant tumour, not otherwise specified.

(7) Technically unsatisfactory.

(8) Carcinoma, not otherwise classified.

\section{Appendix 3}

CRITERIA EXAMINED IN THIS STUDY

(1) Keratinisation.

(2) Intercellular prickles.

(3) Stratification.

(4) Polygonal cell shape.

(5) High nucleocytoplasmic ratio.

(6) Fine stippling of chromatin.

(7) Conspicuous nucleoli.

(8) Basophilic cuffing.

(9) Nuclear moulding.

(10) Stromal desmoplasia.

(11) Formation of rosettes.

(12) Fusiform pattern.

(13) Pagetoid infiltration of surface epithelium.

(14) Formation of acini.

(15) Cribriform pattern.

(16) Papillary pattern.

(17) Lepidic alveolar type pattern.

(18) Mucus formation.

(19) Other features (specify).

\section{Appendix 4}

DEFINITIONS OF NEOPLASMS IN THIS STUDY

(1) Squamous carcinoma was defined as the presence of keratinisation or intercellular prickles, or both. The presence of stratification and of a particular polygonal shape in the tumour cells were also examined to determine their possible value in this diagnosis.
(2) Small cell carcinoma-We are not aware of any unequivocal single diagnostic criterion for small cell carcinoma but recognise the following features, which were sought: high nucleocytoplasmic ratio, fine stippling of chromatin, inconspicuous nucleoli, basophilic cuffing, nuclear moulding, absence of stromal desmoplasia, formation of rosettes, fusiform pattern, and pagetoid infiltration of surface epithelium.

(3) Adenocarcinoma-Any one of the following diagnostic features was deemed sufficient to diagnose adenocarcinoma: formation of acini by tumour cells, production of mucin by tumour cells as demonstrated by the AB/PAS-D technique, cribriform tumour pattern, papillary tumour pattern, and bronchioloalveolar (lepidic) cell pattern

(4) Non-small cell tumour of specified type included adenosquamous carcinoma, giant cell carcinoma, and the carcinoid tumour, which are well described elsewhere.

(5) Non-small cell carcinoma, not otherwise specified was applied to tumours of non-small cell type without a specific direction of differentiation-for example, squamous or adenocarcinoma-in the section examined.

(6) Malignant tumour, not otherwise specified applied to tumours in which it was not possible to state the histogenetic origin-for example, carcinoma, lymphoma, sarcoma.

(7) Technical failure applied to material that was inadequate for diagnostic purposes-for example, because of small size or crushing.

(8) Carcinoma, not otherwise specified applied to tumours that could not be defined as either small cell or non-small cell type with certainty, but nevertheless showed histological features of epithelial differentiation.

We thank Dr D J Girling, Dr A Herbert, Dr D Melcher, Dr J Young, Dr E McGoogan, Dr D Machin, and Mr M K B Parmar for their contributions.

1 Mountain CF, Carr DT, Anderson WAD. A system for the clinical staging of lung cancer. $A \mathcal{F R} 1974$; 120:130-8.

2 Shields TW, Yee J, Conn JH. Relationship of cell type and lymph node metastases to survival after resection of bronchial carcinoma. Am $\mathcal{f}$ Thorac Surg 1975;20: 501-10.

3 Petrovich Z, Stanley K, Cox JD, Doig C. Radiotherapy in the management of locally advanced lung cancer of all cell types. Cancer 1981;48:1335-40.

4 Hande DR, Des Prez RM. Chemotherapy and radiation therapy for non-small cell carcinoma of the lung. Clin Chest Med 1982;3:399-414.

5 Davis D, Stanley KE, Yesner R, Kuang DT, Morris JF. Small cell carcinoma of the lung - survival according to histological subtype. Cancer $1981 ; 47: 1863-6$.

6 World Health Organisation. Histological typing of lung tumours. 2nd ed. International classification of tumours. No 1. Geneva: WHO, 1981

7 Chuang MT, Marchevsky A, Teirstein A, Kirschner PA, Kleinerman J. The diagnosis of lung cancer by fibreoptic bronchoscopy. I. Problems in the histological classification of non-small cell carcinomas. Thorax 1984;39: sification

8 Evans DMD, Shelley G. Respiratory cytodiagnosis: study in observer variation and its relation to quality of material. Thorax 1982;37:259-63.

9 Suprun H, Pedio G, Ruttner JR. The diagnostic reliability of cytological typing in primary lung cancer with review of the literature. Acta Cytol 1980;6:494-9.

10 Roggli VL, Vollmer RT, Greenberg ST, McGavron MH, Spjut HJ, Yessner R. Lung cancer heterogeneity: a blinded randomised study of 100 consecutive cases. Hum Pathol 1985;16:569-78. 